\title{
Efficacy of biomaterial based photocatalytic composite in treating dye pollutants
}

\author{
M. M. Rahman ${ }^{1}$, S. Ahmed ${ }^{2 *}$, Z. Yeasmin ${ }^{2 *}$ and S. M. Masum ${ }^{1}$ \\ ${ }^{I}$ Department of Applied Chemistry and Chemical Engineering, University of Dhaka, Dhaka-1000, Bangladesh \\ ${ }^{2}$ Institute of Glass and Ceramic Research \& Testing (IGCRT), Bangladesh Council of Scientific and Industrial Research \\ (BCSIR), Dhaka-1205, Bangladesh
}

Received: 13 July 2017

Revised: 17 July 2017

Accepted: 18 July 2017

DOI: http://dx.doi.org/10.3329/bjsir.v53i2.36675

\begin{abstract}
A biomaterial based photocatalytic composite, hydroxyapatite- $\mathrm{TiO}_{2}-\mathrm{ZnO}\left(\mathrm{HAp}-\mathrm{TiO}_{2}-\mathrm{ZnO}\right)$ has been developed following a solid-state combustion method while its efficacy was investigated through the photodegradation of (i) aquatic solution of synthetic dye, methylene blue (MB); and (ii) real textile dye effluent. The degradation profile was explored considering several factors, e.g.: (i) initial dye concentration; (ii) illumination span; (iii) dose of photocatalyst; and (iv) $\mathrm{pH}$ of targeted dye solution. The photodegradation was performed in both indoor and outdoor environment using halogen lamp (500 W) and sunlight respectively. Observed photodegradation revealed that though the photocatalytic composite effectively decomposed methylene blue at various extents under different experimental conditions but a dose of $0.5 \mathrm{~g}$ photocatalyst $/ 100 \mathrm{~mL}$ substrate solution $\left(10 \times 10^{-6} \mathrm{M}\right.$ methylene blue solution at $\left.\mathrm{pH} 4\right)$ expedited optimal degradation ( $\left.~ 97 \%\right)$ at 2 hours' time interval. On the other hand though it was possible to degrade the textile effluent to some extent by illuminating through halogen lamp and sunlight but the success rate did not exceed $50 \%$.
\end{abstract}

Keywords: Dye; Hydroxyapatite (HAp); Photocatalyst; Illumination; Composite

\section{Introduction}

Treatment of dye effluents has received significant attention as one of the prime concerns to the researchers, particularly dealing with environmental issues.Since the last three decades, researchers are stringently working to explore this area and development of an effective, sustainable but environment friendly treatment method is always on the top of the list. Concerning these facts, semiconductor mediated photocatalytic approach which is simply triggered by a UV source is rated as the most effective degradation pathway for the destruction of a wide variety of pollutants (Umar et al., 2016; Ahmed, 2013). The reason behind getting such attention is the high competency and easy-to-use operating procedure of photocatalytic process over the traditional biological and physico-chemical methods,e.g.adsorption, membrane filtration, coagulation, reverse osmosis, air stripping etc. (Ahmed et al., 2011; Kabir et al., 2012) However, among the semiconductors, due to their high photosensitivity, large band gap and non-toxic nature of bare $\mathrm{TiO}_{2}$ and $\mathrm{ZnO}$, have already used as photocatalysts (Ahmed, 2013). In addition to single formatted photocatalyst, recently composite or hybrid format of photocatalyst have been explored by the researchers (Guanghong et al., 2011; Juan et al., 2013; Laila et. al., 2015; Nathanael et al. 2010; Ning et al. 2009; Shariffuddin et al., 2013; Yao et al., 2017) as a better option. Ca-hydroxyapatite (HAp) which is rather well-known as biomaterial has recently been using with $\mathrm{TiO}_{2}$ to develop hybrid photocatalyst with better performance. The reason for using HAp with photocatalyst is the formation of charged $\mathrm{O}^{2 \cdot-}$ species (Nishikawa, 2004) upon UV irradiation of HAp and these $\mathrm{O}^{2 \cdot-}$ species can then react with liquid/gaseous molecules of pollutants causing decomposition. Dye and pigments are an imperative source of water pollution as these are extensively used in textile, plastic, paper, leather and food industries. Globally over $7 \times 10^{5}$ tons of dyes are produced in a year which causes serious pollution as $15 \%$ of produced dye is lost during the dyeing process (Yogendra et al., 2011). Dyes can easily contaminate surface water through their discharge from the dye-manufacturing plants, plastic industries, textile plants, etc. Such contaminated colored water is of course undesirable for both human and aquatic lives. However,

\footnotetext{
*Corresponding author e-mail: shanta_samina@yahoo.com, zenefar@gmail.com
} 
researchers throughout the world have put their effort to degrade the dye-stuffs and so far, a number of dyes have been treated photochemically. Among the synthetic dyes, MB which is a cationic dye (structure: Fig. 1) used for coloring papers, dyeing cotton wools and so on, has been subjected for many photodegradation study. Indeed as a model dye pollutant it gets the first option to the researchers to be used in photodegradation study.

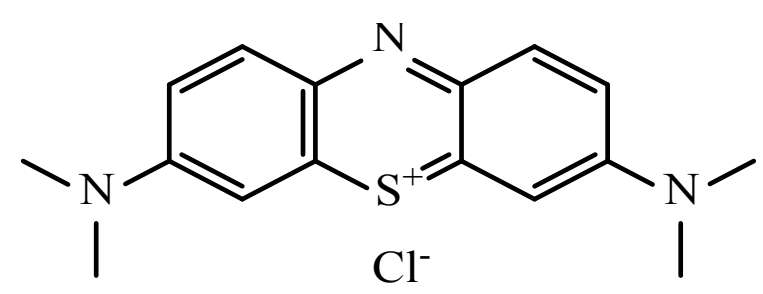

Fig. 1. Structure of Methylene Blue (MB)

However, in order to explore the research in the field of photocatalysis, previously we have developed a hybrid photocatalytic material ( $\mathrm{HAp}-\mathrm{TiO}_{2}-\mathrm{ZnO}$ ) (Alim 2016) using hydroxyapatite which was directly prepared from eggshell. In this present research work we have attempted to optimize the efficiency of that biomaterial based $\mathrm{HAp}-\mathrm{TiO}_{2}-\mathrm{ZnO}$ composite through investigating the photodegradation profile of $\mathrm{MB}$ and real textile effluent.

\section{Materials and methods}

MB, analar grade di-ammonium hydrogen phosphate and $\mathrm{TiO}_{2}$ (rutile) were purchased from E. Merck, Germany while $\mathrm{ZnO}$ (purity 99\%) was obtained from BDH, England. All the chemicals were used without further purification. Eggshells which are the agro-waste were collected from local restaurants and cleaned properly with plenty of water. Textile effluent was collected from a textile industry located in Gazipur, Dhaka, Bangladesh and prior to degradation study the effluent was diluted 50 times with water. All the necessary solutions were prepared using distilled water.

\section{Preparation of biomaterial ( $\left.\mathrm{HAp}-\mathrm{TiO}_{2}-\mathrm{ZnO}\right)$ composite}

Biomaterial based photocatalytic composite (HAp-TiO $-\mathrm{ZnO}$ ) was prepared using a simple solid-state method where at first requisite amounts of eggshell and di-ammonium hydrogen phosphate were mixed in a ball mill (Model: MSK-SFM-1 QM 3SP2) at a rotation speed of 2400 rpm. Then $1 \%$ of each semiconductor oxides $\left(\mathrm{TiO}_{2}\right.$ and $\left.\mathrm{ZnO}\right)$ were added to the mixture with respect to $\mathrm{CaCO}_{3}$ present in eggshell and the ball mill operation was continued for 6 hours maintaining the same rotation speed. Completion of this step yielded the mixture as fine powder which was then sintered at $900^{\circ} \mathrm{C}$ for 30 minutes in an electrical muffle furnace. The desired phases of this hybrid composite was ensured by XRD, FTIR and EDX techniques as described previously (Alim 2016). Fig. 2 shows the photograph of the prepared composite.

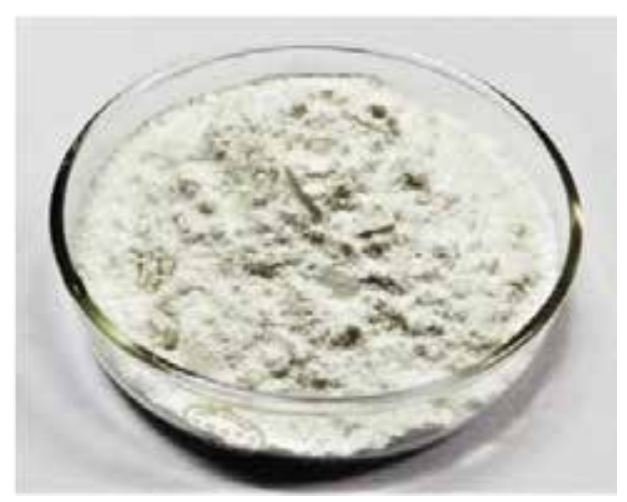

Fig. 2. A photograph of the synthesized (HAp-TiO $2-\mathrm{ZnO}$ ) composite

Treatment of $\mathrm{MB}$ using $\mathrm{HAp}-\mathrm{TiO}_{2}-\mathrm{ZnO}$ composite under illumination (indoor and outdoor)

To investigate the photodegradation efficiency of the HAp- $\mathrm{TiO}_{2}-\mathrm{ZnO}$ composite halogen lamp (500W) was used to facilitate indoor illumination while sunlight was the source of outdoor UV light. The degradation profile was explored considering several factors, e.g.: (i) initial dye concentration $\left(10.0 \times 10^{-6}, 12.5 \times 10^{-6}, 15.0 \times 10^{-6}, 17.5 \times 10^{-6}\right.$ and $\left.20.0 \times 10^{-6} \mathrm{M}\right)$; (ii) illumination span (maintaining $15 \mathrm{~min}$. interval); (iii) dose of photocatalyst $(0.25,0.50$ and $0.75 \mathrm{~g})$; (iv) $\mathrm{pH}(2.05$, $4.14,6.02,8.03,10.04,12.00)$ of targeted dye solution as adjusted either by $\mathrm{HCl}$ or $\mathrm{NaOH}$. Experimental protocol was similar to our previous approach (Ahmed et al. 2011; Kabir et al. 2012). However, briefly, $100 \mathrm{~mL}$ of $\mathrm{MB}$ solution with requisite amount of photocatalyst was introduced in the batch reactor (made of pyrex) and exposed to illumination. An IR filter filled with distilled water was used to concise the wavelength between 200-800 nm. Moreover, such arrangement also helped to reduce the overheating of the reactor. Illumination was continued for 3 hours but after regular time intervals (15 min.), illuminated MB solution was centrifuged to get clear solution and then absorbance was recorded at $664 \mathrm{~nm}$ using UV-vis spectrophotometer (Hitachi UV-Vis double beam spectrophotometer, U-2910). The difference between the absorbance of initial concentration of MB (i.e. without illumination) and absorbance aftert time illumination provided the $\%$ of photodegradation which 
ultimately disclosed the efficiency of the composite. Following equation (Buazar et al. 2015; Ahmed et al. 2011) was used to calculate the $\%$ of degradation.

$$
\% \text { of photodegradation }=\left(\frac{A_{0}-A_{t}}{A_{0}}\right) \times 100
$$

where, $\mathrm{A}_{0}=$ initial absorbance, $\mathrm{A}_{\mathrm{t}}=$ absorbance at time $t$

The schematic diagrams of the degradation experiments for both the halogen lamp and sunlight are shown in Fig. 3.

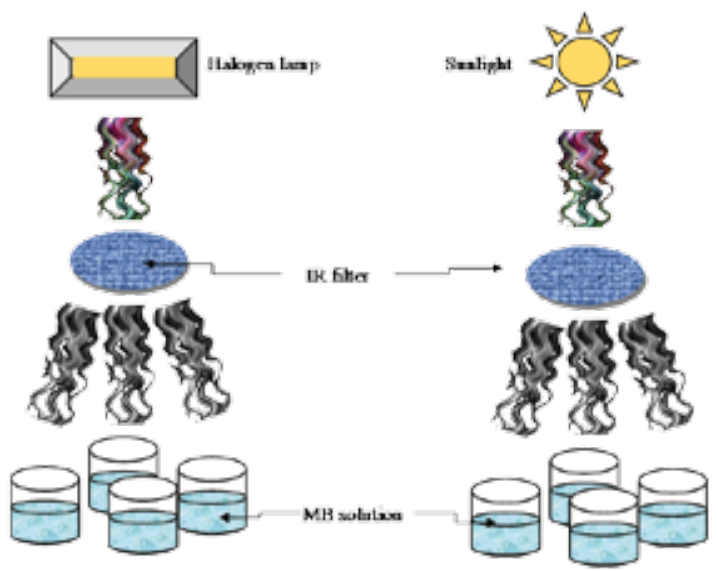

Fig. 3. Schematic diagram of experimental protocol

A light meter (CEM DT-1308) was used to measure the intensity of irradiation sources and was found to be within the range of 10.4-10.7 klx and 39.5-42.0 klx for halogen lamp and sunlight respectively.

Treatment of real textile effluent using halogen lamp and sunlight

In order to treat textile effluents using $\mathrm{HAp}-\mathrm{TiO}_{2}-\mathrm{ZnO}$ composite $100 \mathrm{~mL}$ of 50 times diluted textile effluent together with $0.5 \mathrm{~g}$ catalyst was placed in the pyrex reactor and illumination was provided for 120 minutes using halogen lamp and sunlight.The illuminated effluents were analyzed periodically at 30-minute interval following the same procedure as described in the previous section.

\section{Results and discussion}

Treatment of $\mathrm{MB}$ using $\mathrm{HAp}-\mathrm{TiO}_{2}-\mathrm{ZnO}$ composite without UV illumination

Prior to the photodegradation study, $10 \times 10^{-6} \mathrm{M} \mathrm{MB}$ solution (monomer form) in aqueous medium was treated at ambient temperature using $\mathrm{HAp}-\mathrm{TiO}_{2}-\mathrm{ZnO}$ composite but no UV illumination was facilitated. The ratio of $\mathrm{HAp}-\mathrm{TiO}_{2}-\mathrm{ZnO}$ composite and MB solution was $0.5 \mathrm{~g} / 100 \mathrm{~mL}$.After regular time intervals (30 mins.), the absorption maxima of $\mathrm{MB}$ monomer was monitored at $\lambda_{\max } 664 \mathrm{~nm}$ (Mills and Wang, 1999) and a slight change in MB concentration was observed after 15 hrs (as shown in Fig. 4) which revealed that no degradation but adsorption $(\sim 17 \%)$ is occurred without UV illumination.This adsorption phenomenon was further validated through comparing a parallel experimental data in the dark without using $\mathrm{HAp}-\mathrm{TiO}_{2}-\mathrm{ZnO}$ composite which showed no change in $\mathrm{MB}$ concentration i.e. no degradation occurred without catalyst as well as without photo excitation.

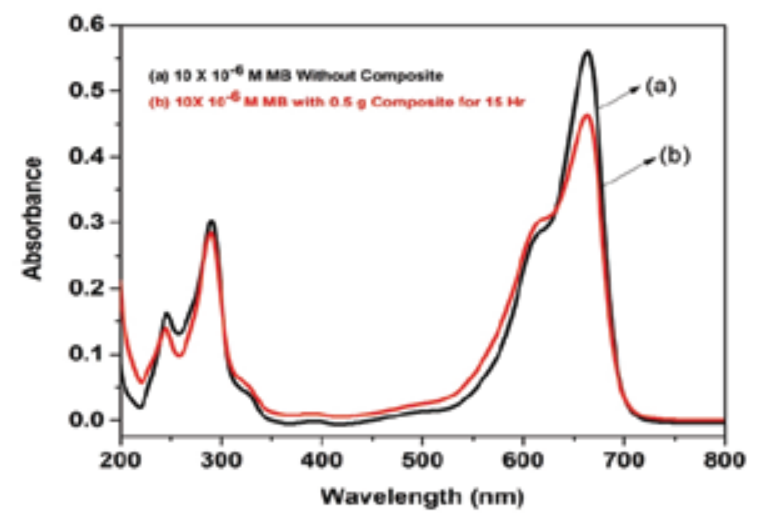

Fig. 4. UV-Vis spectra of (a) MB without the composite and (b) MB with the composite for 15 hours in the dark

Photodegradation study of MB irradiating with halogen lamp

(i)

Effect of initial MB concentration

Given in Fig. 5 is the photodegradation of $\mathrm{MB}$ where initial dye concentration was varied $\left(10.0 \times 10^{-6}, 12.5 \times 10^{-6}, 15.0 \times 10^{-6}\right.$, $17.5 \times 10^{-6}$ and $\left.20.0 \times 10^{-6} \mathrm{M}\right)$ but illumination time (30 min.) and dose of photocatalyst was fixed $(0.5 \mathrm{~g} / 100 \mathrm{~mL})$. Clearly, the Fig. 5 shows that the highest degradation (51\%) was achieved in case of lowest initial MB concentration while this percentage was drastically reduced (30\%) for higher MB concentration. Such observation was in line with earlier observations (Anas et al., 2015; Byrappa et al., 2006). The initial concentration plays a key role in expediting degradation process since, higher the dye concentration more and more organic particles are absorbed on the photocatalyst surface. On the other hand since illumination is also provided for a fixed time with a constant intensity effect, the numbers of $\mathrm{OH}$ and $\mathrm{O}_{2}^{2--}$ species formed on the surface are also constant. Hence the availability of these active species becomes insufficient to attack more and more MB molecules for 
effective photodegradation at higher initial concentration which ultimately slowed down the degradation efficiency at higher concentration of $\mathrm{MB}$.

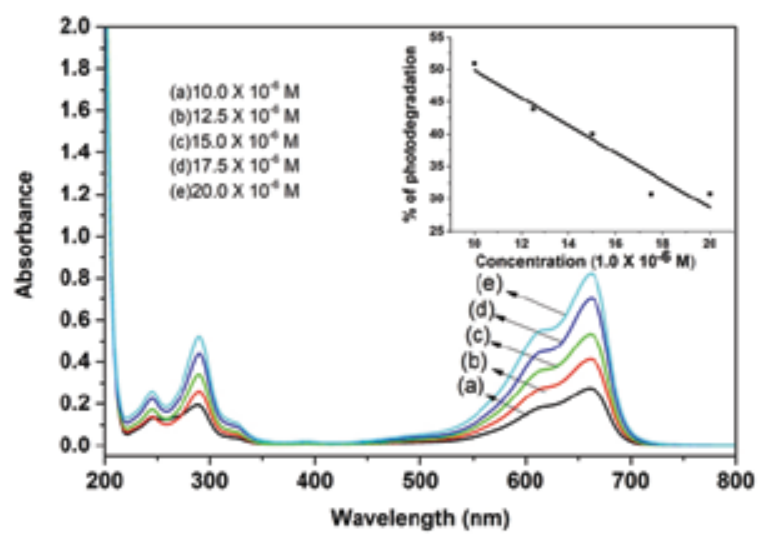

Fig. 5. UV-Vis spectra of MB solution of different concentration and percentage of photodegradation of different concentration MB solution after 30 minutes of irradiation

(ii)

\section{Effect of irradiation time}

The photodegradation performance of $\mathrm{HAp}_{-} \mathrm{TiO}_{2}-\mathrm{ZnO}$ composite as a function of illumination time is shown in Fig. 6. The initial concentration of MB was $10.0 \times 10^{-6} \mathrm{M}$ while the dosage of the composite was $0.5 \mathrm{~g} / 100 \mathrm{~mL}$. It is clearly evident from Fig. 6 that irradiation span is an important aspect of photodegradation phenomenon. The intensity of degradation become more prominent with time and almost complete discoloration of the MB $(\sim 97 \%)$ was achieved after 105 minutes of irradiation. This is because the degradation process mediated by photocatalyst usually occurs on the surface of the catalyst where $\cdot \mathrm{OH}$ and $\mathrm{O}_{2}{ }^{2-*}$ radicals exist to initiate photocatalytic degradation. The formation of these radicals upturns with irradiation time and as a result more

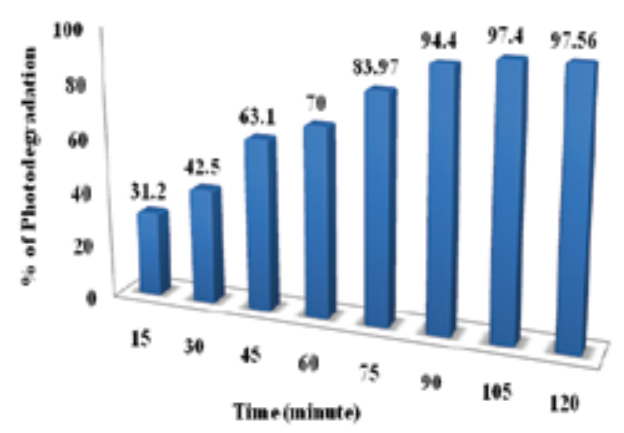

Fig. 6. Percentage of photodegradation of 1010-6 M MB with time active sites take part in the degradation reaction. As a result the dye is completely degraded in the course of illumination time. Such degradation trend satisfies previous observation of Murugesan et al. (2002).

\section{(iii)}

\section{Effect of photocatalyst dose}

Keeping initial MB concentration $\left(10 \times 10^{-6} \mathrm{M}\right)$ and irradiation time (105 min.) constant, the efficiency of $\mathrm{HAp}-\mathrm{TiO}_{2}-\mathrm{ZnO}$ composite in destructing $\mathrm{MB}$ was also examined as a function of photocatalyst dose $(0.25,0.50$ and $0.75 \mathrm{~g} / 100 \mathrm{~mL} \mathrm{MB})$ and the respective degradation profile is depicted in Fig. 7. Clearly, the increase in the amount of catalyst speed up the degradation percentage and initially a sharp change in degradation pattern was observed. The photodegradation percentage was almost equal for the $0.5 \mathrm{~g}$ and $0.75 \mathrm{~g}$ photocatalytic composite under the present experimental condition. The maximum percentage of photodegradation was nearly about $97 \%$. This is because when the amount of photocatalyst was increased from $0.25 \mathrm{~g}$ to $0.50 \mathrm{~g}$, more active sites became available to trigger the degradation process which eventually increased degradation percentage.

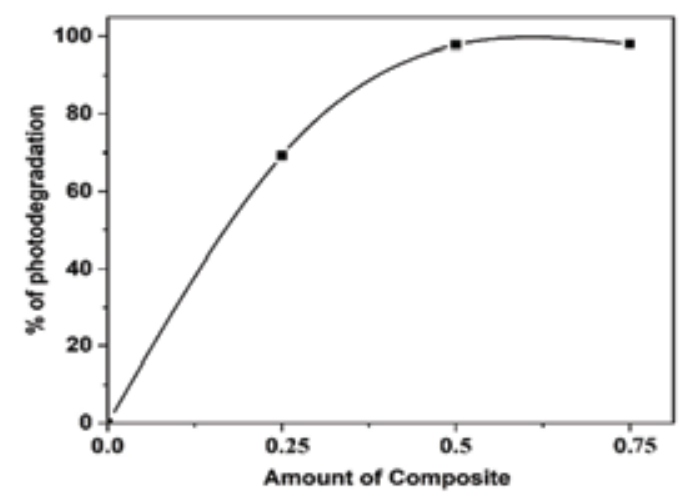

Fig. 7. Photodegradation pattern of $10.0 \times 10^{-6} \mathrm{M} \mathrm{MB}$

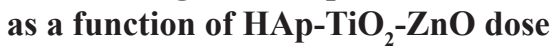

\section{Effect of pH of substrate (MB) solution}

The $\mathrm{pH}$ is a multifarious factor since it is associated to the ionization state of the surface as well as to that of reactants and products. Usually, $\mathrm{pH}$ plays an important role in the characteristics of dye and is one of the most important parameters that influence the photodegradation processes. Fig. 8 represents the degradation of $\mathrm{MB}$ with $\mathrm{pH}$. Nevertheless, from this graph it is evident that, after 105 minutes of illumination, the magnitude of degradation in highly acidic medium was lowest and it worked well when $\mathrm{pH}$ scale was in basic direction. Such phenomenon is interconnected with the surface-charge properties of the photocatalyst. At higher $\mathrm{pH}$, excess of $\mathrm{OH}^{-}$anions are readily 
available, which accelerates photogeneration of hydroxyl radicals and as a result degradation efficacy increases (Chakrabarti et al., 2004; Chu et al., 2007).

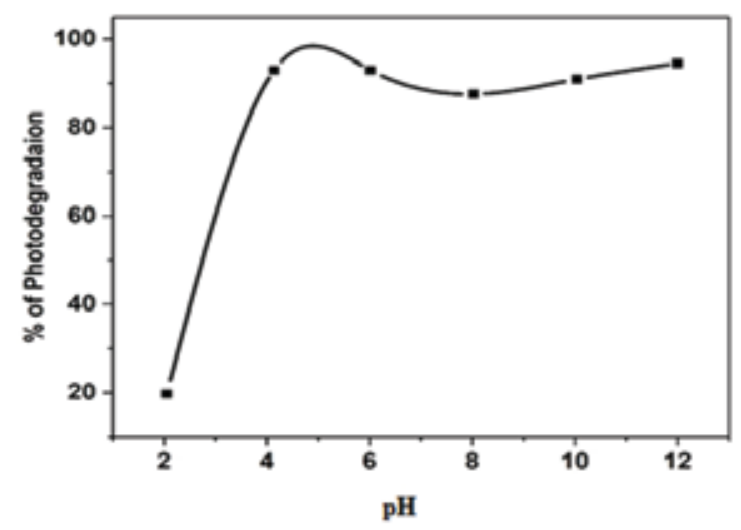

Fig. 8. Effect of $\mathrm{pH}$ on the percentage of photocatalytic degradation of $10.0 \times 10^{-6} \mathrm{M} \mathrm{MB}$ solution

\section{Photodegradation study of MB irradiating with sunlight}

Since the intensity of illumination source greatly affects the photo-mineralization process, the efficacy of the composite was further examined through monitoring the degradation of MB under sunlight. Both spectral and graphical (inset) representations (Fig. 9) showed thatin this case,more than $96 \%$ photodegradation was completed within $30 \mathrm{~min}$. and $99 \%$ degradation was accomplished by $120 \mathrm{~min}$. In this case, degradation rate was higher than that of halogen lamp irradiation. This is because the overall energy input to a photocatalytic process is reliant on the intensity of illumination source (Ahmed et al., 2011). Therefore enhanced intensity of sunlight accelerated the degradation of MB.

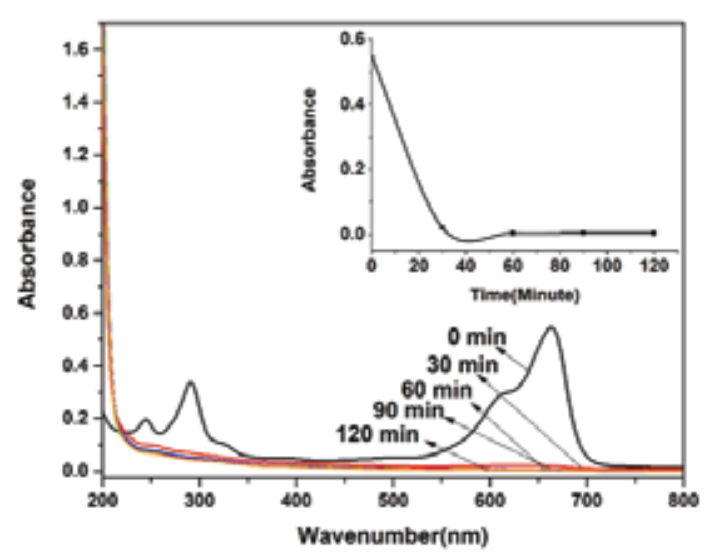

Fig. 9. Time dependent absorption spectra of $10 \times 10^{-6}$ M MB solution illuminated under sunlight.
Photodegradation of real textile effluent under halogen lamp and sunlight

The degradation data of textile effluent as tabulated in Table I revealed that though it was possible to degrade the textile effluent to some extent by illuminating through halogen lamp and sunlight but again the success rate did not exceed $50 \%$. The plausible reason for such response might be the complex nature of the real effluent which needs further investigation.

Table I. Photodegradation of real textile effluent under halogen lamp and sunlight

\begin{tabular}{ccc}
\hline \multirow{2}{*}{$\begin{array}{c}\text { Illumination time } \\
(\text { min. })\end{array}$} & \multicolumn{2}{c}{ Illumination source } \\
\cline { 2 - 3 } & $\begin{array}{c}\text { Halogen lamp } \\
(500 \mathrm{~W})\end{array}$ & Sunlight \\
\hline 0 & 0 & 0 \\
30 & 2.74 & 38.83 \\
60 & 6.85 & 39.66 \\
90 & 23.29 & 42.35 \\
120 & 32.88 & 45.88 \\
\hline
\end{tabular}

\section{Conclusion}

It was found from this investigation that $\mathrm{HAp}_{-} \mathrm{TiO}_{2}-\mathrm{ZnO}$ composite is capable to degrade methylene blue dye following an efficient manner. The reaction was optimized by considering several parameters e.g.: (i) initial dye concentration; (ii) illumination span; (iii) dose of photocatalyst; and (iv) $\mathrm{pH}$ of targeted dye solution. The efficiency was higher at the sunlight compared to halogen lamp. Under halogen lamp $0.5 \mathrm{~g}$ of composite completely degrade $100 \mathrm{~mL}$ of $10 \times 10^{-6} \mathrm{M}$ MB solution within $90 \mathrm{~min}$. whereas it only took $30 \mathrm{~min}$. in the presence of sunlight. Photodegradation of textile effluent using $\mathrm{HAp}_{-} \mathrm{TiO}_{2}-\mathrm{ZnO}$ photocatalytic composite was comparatively lower than the photodegradation of methylene blue. The reason behind this might be the multifarious mixture form of the unknown textile effluent which hinders the active sites of the photocatalytic composite to be active enough to trigger the degradation reaction effectively. However, the end product formed as a result of photodegradation or decolorization of the effluent is also unknown in this case. Therefore, further experimental approaches arc necessary to detect the photodegradation product.

\section{Acknowledgements}

We are grateful to BCSIR authority for approving the MS studentship of M M Rahman. The financial support from 
IGCRT, BCSIR and from the Ministry of Science and Technology, Govt. of Bangladesh are highly appreciated.

\section{References}

Ahmed S (2013), Interfacial photocatalytic processes, Physical Chemistry: An Indian Journal 8(4): 150-156.

Ahmed S, Jahan SA, Zaman M, Yeasmin Z and Ahsan M (2011), Photodegradation of Methylene Blue Mediated by Rice Husk Ash (RHA)-TiO ${ }_{2}$ Composite, Bang. J. of Sci. and Ind. Res. 46(1): 17-26. (DOI: http://dx.doi.org/10.3329/bjsir.v46i1.8100

Alim MA (2016), Development of hydroxyapatite - $\mathrm{TiO}_{2}$ $\mathrm{ZnO}$ composite material and its application as photocatalyst for waste water treatment, MS Thesis, University of Dhaka, Bangladesh.

Anas S, Abdellatif A, Soufiane T, Layachi K, Mohammed B, Fouad B and Mohammed EK (2015), Study of the photocatalytic degradation of methylene blue dye using titanium-doped hydroxyapatite, Mediterranean J. of Chem. 4(1): 59-67. DOI: 10.13171/mjc.4.1.2015.16.01.20.30/salhi

Buazar F, Alipouryan S, Kroushawi F and Hossieni S (2015), Photodegradation of odorous 2-mercaptobenzoxazole through zinc oxide/hydroxyapatite nanocomposite, Applied Nanoscience 5: 719-729. DOI: 10.1007/s13204-014-0368-4

Byrappa K, Subramani AK, Ananda S, Rai K, Dinesh R and Yoshimura M (2006), Photocatalytic degradation of rhodamine B dye using hydrothermally synthesized ZnO, Bull. Mater. Sci. 29(5): 433-438. DOI: 10.1007/BF02914073

Chakrabarti S and Dutta BK (2004), Photocatalytic degradation of model textile dyes in waste water using $\mathrm{ZnO}$ as semiconductor catalyst, J. of Haz. Mat. B112: 269-278. DOI: 10.1016/j.jhazmat.2004.05.013

Chu W, Choy W and So T (2007), The effect of solution $\mathrm{pH}$ and peroxide in the $\mathrm{TiO}_{2}$-induced photocatalysis of chlorinated aniline, J. of Haz. Mat. 141(1): 86-91. DOI: 10.1016/j.jhazmat.2006.06.093

GuanghongS; Lili Q and Yaqin M (2011), Preparation of $\mathrm{TiO}_{2} /$ hydroxyapatite composite and its photocatalytic degradation of methyl orange, J. Env. Engg. 137(7): 611-616. DOI: 10.1061/ (ASCE) EE. 1943-7870.0000357

Juan X, Xiaocai M, Zhao Z Ping L,Lan Y, Li B,Xiaorui G and Yu W (2013), Preparation of titania/hydroxyapatite $\left(\mathrm{TiO}_{2} / \mathrm{HAp}\right)$ composite photocatalyst with mosaic structure for degradation of pentachlorophenol, Mat. Lett. 110: 57-60. DOI: 10.1016/j.matlet.2013.07.108

Kabir MH, Kabir MF, Nigar F, Ahmed S, Mustafa AI and Ahsan M (2012), Preparation and characterization of rice husk ash (RHA)-TiO/ $\mathrm{ZnO}$ composites and its application in treating effluents from textile industries, Bang. J. of Sci. and I. Res. 47(4): 445-448. DOI: 10.3329/bjsir.v47i4.14075

Laila M, Al-Harbi, Samia AK, Islam HAEM and Eman ZH (2015), The photocatalytic activity of $\mathrm{TiO}_{2}-$ zeolite composite for degradation of dye using synthetic UV and Jeddah sunlight, J. of Nanomat., Article ID 565849: 16(1): 1-6. DOI: 10.1155/2015/565849

Mills A and Wang J (1999), Photobleaching of methylene blue sensitized by $\mathrm{TiO}_{2}$ : an ambiguous system, $J$. of Photochem. and Photobiol. A: Chem. 127(1): 123-134. DOI: 10.1016/S1010-6030(99)00143-4

Murugesan V and Sakthivel S (2002), Photocatalytic degradation of leather dyes in aqueous solution using solar/UV illuminated $\mathrm{TiO}_{2} / \mathrm{ZnO}$, Proceedings of International Symposium on Environmental Pollution Control and Waste Management, pp 654-659.

Nathanael AJ, Mangalaraj D, Chen PC and Ponpandian N (2010), Mechanical and photocatalytic properties of hydroxyapatite/titania nanocomposites prepared by combined high gravity and hydrothermal process, Comp. Sci. and Tech. 70: 419 - 426. DOI: 10.1016/j.compscitech.2009.11.009

Ning M, Xinfei F, Xie Q and Yaobin Z (2009), $\mathrm{Ag}-\mathrm{TiO}_{2} / \mathrm{HAP} / \mathrm{Al}_{2} \mathrm{O}_{3}$ bioceramic composite membrane: Fabrication, characterization and bactericidal activity, J. of Mem. Sci. 336: 109-117. DOI: 10.1016/j.memsci.2009.03.018

Nishikawa H (2004), Radical generation on hydroxyapatite by UV irradiation, Mat. Lett. 58(1): 14-16. DOI: 10.1016/S0167-577X(03)00396-3

Shariffuddin JH, Jones MI and Patterson DA (2013), Greener photocatalysts: Hydroxyapatite derived from waste mussel shells for the photocatalytic degradation of a model azo dye wastewater, Chem. Eng. Res. and Des. 91(9): 1693-1704. DOI: 10.1016/j.cherd.2013.04.018

Umar K, Aris A, Ahmad H, Parveen T, Jaafar J, Majid ZA, Reddy AVB and Talib J (2016), Synthesis of visible light active doped $\mathrm{TiO}_{2}$ for the degradation of organic pollutants-methylene blue and glyphosate, J. Anal. Sci. Technol. 7(29): 1-8. DOI: DOI: 10.1186/ S40543-016-0109-2.

Yao J, Zhang Y, Wang Y, Chen M, Huang Y, Cao J, Ho W and Lee SC (2017), Enhanced photocatalytic removal of NO over titania/hydroxyapatite ( $\left.\mathrm{TiO}_{2} / \mathrm{HAp}\right)$ composite with improved adsorption and charge mobility ability, RSC Advances 7: 24683 - 24689. DOI: $10.1039 / \mathrm{C} 7 \mathrm{RA} 02157 \mathrm{G}$

Yogendra K, Mahadevan K, Naik S and Madhusudhana N (2011), Photocatalytic activity of synthetic $\mathrm{ZnO}$ composite against Coralene red F3BS dye in presence of solar light, Intl J. of Env. Sci. 1: 839 - 846. 